\title{
A Study of Glass Composition and Crizzling in Two Claude Laurent Glass Flutes from the Library of Congress
}

\author{
Andrew Buechele ${ }^{1}$, Lynn Brostoff ${ }^{2}$, Isabelle Muller ${ }^{1}$, Carol Lynn Ward-Bamford ${ }^{2}$ and Xiaogang Xie ${ }^{1}$ \\ 1. The Catholic University of America, Vitreous State Laboratory, Washington, DC, USA. \\ ${ }^{2 .}$ Library of Congress, Washington, DC, USA.
}

Claude Laurent, a French clockmaker, started making musical flutes out of glass in the early $19^{\text {th }}$ century. He was granted a patent in 1806 for "une flute en cristal" and won a silver medal that year at the Paris Industrial Exposition for his invention. Laurent believed that glass had many desirable qualities as a material for fabrication of flutes. Certainly they were impressive to look at, and many were presented to European heads of state during Laurent's lifetime, but, according to Dayton C. Miller (1866-1941), an Ohio physicist and amateur flutist, they were not exceptional in their tonal quality. Miller was also a collector who amassed over 1700 flutes and wind instruments which he donated to the Library of Congress in 1941. Within that collection are 18 of the approximately 140 Laurent glass flutes known to exist worldwide [1].

The flutes have become the subject of a research project directed toward a deeper understanding and appreciation of these unique instruments, and toward providing valuable data for their preservation. Although Laurent referred to his flutes as "crystal," XRF analysis carried out at the Library of Congress has shown that only two of the 18 Miller flutes are made of leaded crystal glass. Most of the rest are made of potash glass, an alkali glass with potassium as the principal component. Some of the flutes in the collection exhibit evidence of glass deterioration, which results when the humidity in the air diffuses into the glass and hydrates and leaches out alkali ions from the glass structure. This endangers the integrity of glass matrix and can be visible as crizzling, a fine network of microscopic cracks in the alkali-depleted surfaces. In advanced stages, flaking is evident in this layer. Both conditions scatter light and cause the glass to appear frosty to the naked eye.

The Vitreous State Laboratory (VSL) at The Catholic University of America (CUA) was approached by Dr. Lynn Brostoff of the Library of Congress and asked to help to characterize the potash glass more completely and better understand the degradation process. Initial SEM-EDS examination of a very small unpolished chip taken from a previously damaged extra foot joint of a flute identified as 1235 confirmed that the major components of the glass are $\mathrm{K}_{2} \mathrm{O}, \mathrm{SiO}_{2}$, and $\mathrm{CaO}$, plus a small amount of $\mathrm{Na}_{2} \mathrm{O}$. Subsequently, additional material was collected from the damaged joint of 1235 to provide sufficient material ( $\sim 60 \mathrm{mg}$ ) to conduct Direct Coupled Plasma (DCP) and X-ray fluorescence (XRF) spectroscopic analysis of the glass as noted in Table 1. Quantitative results confirm the major components present, as well as a number of minor and trace elements. At the same time that material was gathered from 1235, a second flute, 717, which also exhibits crizzling, was made available for microsampling at the site of previous damage. A perforation was noted at the base of a decorative Vgroove in the surface of flute 717, which may have been facilitated by crizzling. Cautious pressure in the perforated area at the base of the groove resulted in the extraction of two small chips that contain portions of both the original inner and outer surfaces of the flute body. These chips were mounted in epoxy and polished to expose a cross-section perpendicular to the longitudinal axis of the flute, so that both inner and outer surface could be observed in the SEM. Figure 1 displays a backscattered electron image (BEI) micrograph of the mount, showing modified layers about $30 \mu \mathrm{m}$ thick on both the inner and 
outer surfaces of either chip. Compositional profiles were acquired by energy dispersive spectroscopy (EDS) throughout the modified layers of both chips of flute 717 . Figure 2 is representative of the behavior seen in all profiles. In brief, in the modified layer, potassium decreases to about $1 / 3$ its value in the original glass, while sodium drops below the detections limit for analytical conditions used; at the same time, oxygen seems to increase by 4 to $5 \mathrm{wt} \%$, perhaps indicating some water retention. The aforementioned transitions are relatively abrupt, while calcium and silicon remain relatively constant across the reaction interface. Comparison of compositions of the glasses used in the fabrication of flutes 1235 and 717 using SEM-EDS on mounted, polished chips also shows that $\mathrm{K}_{2} \mathrm{O}$ is about 4 wt $\%$ higher in 717 , which is consistent with a greater degree of crizzling seen in this flute.

The layers observed in the above microsamples represent the result of about 200 years of exposure to ambient atmospheric moisture, as well as the breath of flutists. To further study and understand the degradation process in the glass that are taking place on both interior and exterior surfaces of flute joints replications of the two representative Laurent compositions determined above are being melted to engender model samples. Methods of accelerated testing used at VSL to assess the durability of nuclear waste-glass candidates will be applied to induce attack of these replications. In addition to providing a window on the kinetics of the aging reactions in the flute glasses, a correlation of the short term results of an accelerated test with the actual effects of aging under ambient atmospheric conditions will be possible.

References:

[1] "Anatomy of the Flute”, Library of Congress Magazine, 3, No. 5, (2014), p. 4.

\begin{tabular}{|c|c|c|c|c|c|c|c|}
\hline \multirow{2}{*}{ Flute ID } & $\begin{array}{c}\text { Analyses } \\
(\mathrm{wt} \%)\end{array}$ & $\mathrm{Al}_{2} \mathrm{O}_{3}$ & $\mathrm{CaO}$ & $\mathrm{K}_{2} \mathrm{O}$ & $\mathrm{Na}_{2} \mathrm{O}$ & $\mathrm{SiO}_{2}$ & Others \\
\hline \multirow{3}{*}{1235} & $\mathrm{DCP}$ & 0.36 & 3.38 & 15.54 & 0.77 & 79.04 & 0.92 \\
\cline { 2 - 8 } & $\mathrm{XRF}$ & 0.66 & 3.48 & 16.49 & 0.68 & 77.88 & 0.80 \\
\cline { 2 - 8 } & $\mathrm{SEM}$ & 0.34 & 3.69 & 17.18 & 0.63 & 78.03 & 0.13 \\
\hline 717 & SEM & 0.00 & 3.49 & 21.02 & 0.68 & 74.45 & 0.36 \\
\hline
\end{tabular}

Table 1. Summary Analyses of the Flute Samples (others include $\mathrm{Cl}, \mathrm{SO}_{3}, \mathrm{~B}_{2} \mathrm{O}_{3}, \mathrm{BaO}, \mathrm{Fe}_{2} \mathrm{O}_{3}, \mathrm{Li}_{2} \mathrm{O}$, $\mathrm{MgO}, \mathrm{MnO}, \mathrm{NiO}, \mathrm{P}_{2} \mathrm{O}_{5}, \mathrm{Rb}_{2} \mathrm{O}, \mathrm{TiO}_{2}, \mathrm{ZnO}, \mathrm{ZrO}_{2}$, in the range of 0.002 to 0.17 ).

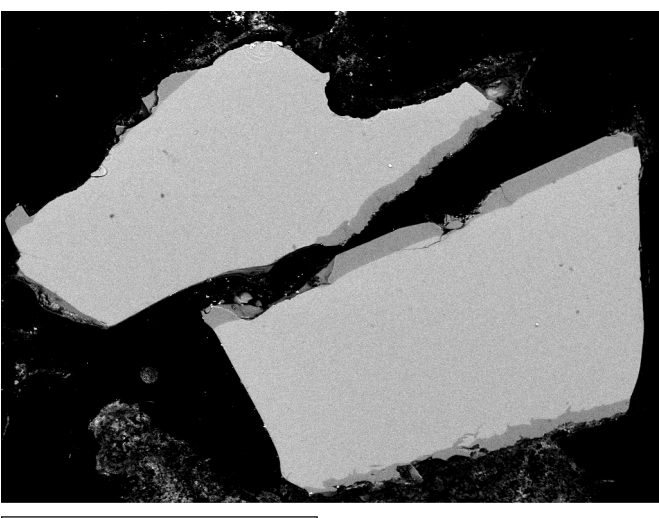

$500 \mu \mathrm{m}$

Figure 1. BEI micrograph of chips from flute 717 wall showing a modified layer.

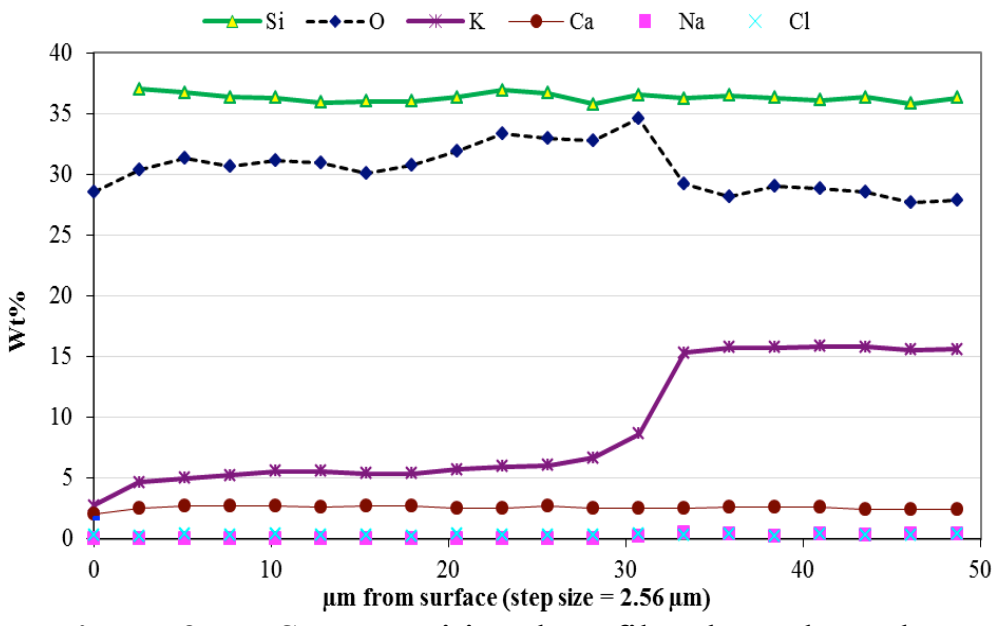

Figure 2. EDS compositional profiles throughout the modified layer in flute 717 . 